\title{
Vocabulary Instruction in ELT: A Neglected Situation?
}

\author{
Yuanyuan Zhu \\ School of English and Education, Center for Foreign Literature and Culture, Guangdong University of Foreign Studies, \\ Guangzhou, China \\ Email:gwyyzhu@163.com
}

How to cite this paper: Zhu, Y.Y. (2020) Vocabulary Instruction in ELT: A Neglected Situation? Open Access Library Journal, 7: e5982.

https://doi.org/10.4236/oalib.1105982

Received: November 20, 2019

Accepted: December 31, 2019

Published: January 3, 2020

Copyright $\odot 2020$ by author(s) and Open Access Library Inc.

This work is licensed under the Creative Commons Attribution International License (CC BY 4.0).

http://creativecommons.org/licenses/by/4.0/

\section{(c) (i) Open Access}

\begin{abstract}
This article reports on an empirical study aiming to investigate the impact of vocabulary instruction on the teaching and learning of vocabulary in senior middle schools in China. Vocabulary instruction offers the teachers and the students with systematic vocabulary guidance. The differences between before and after the intervention of vocabulary instruction are discussed to evaluate its impact. Data are collected from the Teacher Log, the Student Questionnaire and the Follow-up Teacher Interview. Based upon a one-semester experiment with participants from two schools, it has been found: 1) vocabulary instruction could work more effectively than a word list in stimulating the students' interest in vocabulary learning and in developing their vocabulary; 2) National College Entrance Examination System in China and institutional resistance to change are the main reasons that vocabulary instruction is neglected in English language teaching (ELT).
\end{abstract}

\section{Subject Areas}

Education, Linguistics

\section{Keywords}

Vocabulary Instruction, Impact, English Language Teaching

\section{Introduction}

Vocabulary instruction functions as training material and helps learners learn vocabulary more effectively and independently. Different from a word list (a list of individual words with their equivalent translations in the mother tongue), a vocabulary instruction provides more information about vocabulary, such as knowledge of a word and its relevant learning strategies. In order to introduce both 
teachers and students a systematic guidance to effective vocabulary learning strategy (VLS) in a systematic way, more recently published EFL (English as a foreign language) course books have included a vocabulary instruction (Zhu, 2017) [1].

However, it seems that not all teachers have realized the necessity of a vocabulary instruction and most of them in practice tend to skip it, taking it for granted that it is not worth spending time on it. This is partly because of "the habit": teaching by word lists. Meanwhile, the assumption that students themselves can learn words without any help is another possible reason resulting in the ignorance of vocabulary instruction. As a result, most students are still learning vocabulary by memorizing a word list after graduation from the middle school. Research shows that rote memorization is popularly employed among freshmen in the university and "they often complained about the burden of memorizing new words and the easy-forgetting characteristic of remembering" (Chen, 2002, p. 17) [2].

In this respect, to show the impact of a vocabulary instruction appears to be important and necessary because it may help both teachers and students reconsider the value of "vocabulary instruction" in the course book. Thus, it is the purpose of this study to investigate the impact of a vocabulary instruction on the teaching and learning of vocabulary in senior middle schools in China based on an empirical research.

\section{Background}

The essential background to this study will be mainly concerned with English education in senior middle schools in China.

\subsection{Significance of English Education in Senior Middle Schools}

With the development of globalization, English as one of world's languages is attracting more and more attention in schools and colleges around China. Nowadays pupils in primary schools from the first year have been provided with English classes. At senior middle schools, English is not only a compulsory subject for students but also a compulsory subject in the National College Entrance Examination. To highlight its importance, a 45- minute English class is taught every day throughout the week in most senior middle schools.

\subsection{Teaching and Learning of Vocabulary in Senior Middle Schools}

Traditionally, vocabulary is mainly taught by a word list which is attached at the end of a textbook; very little knowledge of vocabulary is built; and few VLS are introduced to the students in class. In a word, little effort is made to teach students strategies for learning vocabulary. As for students, most of them assume that learning vocabulary is to know the pronunciation, form and meaning of a new word in the word list and then learn it by heart. Frankly speaking, they have been working very hard on it, but the effect does not seem satisfying. They com- 
plain often that they tend to forget the words, not to say applying them into practice.

\section{Literature Review}

Learner training for language learning aims to help language learners to learn how to learn, in other words, to improve learning effectiveness by giving learners the tools to make them more capable of independent learning (Dickinson, 1992) [3]. Ellis and Sinclair (1989, p. 2) [4] define it as follow:

Learner training aims to help learners consider the factors that affect their learning and discover the learning strategies that suit them best. It focuses their attention on the process of learning so that the emphasis is on how to learn rather than on what to learn. Learner training, therefore, aims to provide learners with the alternatives from which they can make informed choices about what, how, why, when and where they learn.

Ellis and Sinclair's definition on learner training emphasizes the importance of learning strategies in the process of learning. In this respect, it appears that the purpose of learner training in vocabulary learning is to raise students' awareness of alternative ways of learning vocabulary and provide them with choices of VLS. Then they will be able to choose the one(s) that suit their learning needs. Hatch and Brown (1995, p. 422) [5] argue that "the key in all vocabulary teaching is to keep motivation high" and that learners will be motivated if they have a measure of learning autonomy. Accordingly, learner training appears to be necessary in successful vocabulary learning and it helps learners to become more independent.

The points above indicate that a systematic and principled approach to instruction in vocabulary is necessary to both the teacher and the students and that vocabulary cannot be left to take care of itself. Also, Anderson (1994) [6] emphasizes the necessity of cultivating vocabulary. Oxford and Scarcella (1994) [7] suggest that learners should be provided with systematic vocabulary instruction, opportunities to learn vocabulary through context and specific strategies for acquiring words and shown how to learn words outside of their classes.

In addition, language updates continuously with the development of society. Thus, it seems impossible to guarantee that learners may not come across new language knowledge even though they have mastered the language very well at school or college. Take vocabulary, one of topics known to be centrally relevant to language learning, for example. Mastery of the complete lexicon of a language is beyond not only second language or foreign language learners but also native speakers (Schmitt, 2000) [8]. Goulden, Nation, and Read (1990, p. 341-363) [9] counted the number of word families in Webster's Third New International Dictionary (1983), which is one of the largest non-historical dictionaries of English and found that the dictionary contained about 54,241 word families. And recent reliable studies estimate that even educated native speakers of English may have 
a vocabulary size of around 20,000 word families (Schmitt, 2000; Nation, 2001) [8] [10]. The statistics suggests that it is impossible for learners to learn all of lexical items in a classroom situation. Therefore, only by learner training, namely, by introducing systematic methods of vocabulary learning can teachers help their students to learn the huge number of lexical items independently in the future. As Confucius (551 - 479 BC), the great Chinese educator, mentioned, "If you give a man a fish, you feed him for a day; if you teach a man to fish, you feed him for a lifetime".

\section{Methodology}

To investigate the impact of vocabulary instruction on vocabulary teaching and learning, an experiment was designed and carried out. Then, feedback was collected from both teachers and students through a Teacher Log, a Student Questionnaire and a Follow-up Teacher Interview.

\subsection{The Experimental Design}

As Kumar (1996, p. 83) [11] states, "before-and-after design is the most appropriate design for measuring the impact or effectiveness of a program". Therefore, it is employed in this experimental design and aims to compare the differences between before and after vocabulary instruction and to evaluate its impact. To investigate the impact of vocabulary instruction on the teaching and learning of vocabulary in senior middle schools in China, the experimental group was supposed to conduct the vocabulary instruction in semester two of Year one.

It is certain that foreign words are not instantaneously learned. Rather, they are gradually learned over a period of time from numerous exposures. Therefore, it seemed inappropriate to evaluate the effectiveness of the experiment by means of examinations after only one semester study. It was not realistic to expect the students to achieve apparent progress after such a short period. Accordingly, the evaluation of the experiment focused on changes in the teachers and their students' attitude to vocabulary teaching and learning. If most of them regarded that the intervention of a vocabulary section could help them to handle vocabulary, it would be considered that the experimental study had achieved its goal.

\subsection{Sample}

A total of 118 students and two English teachers from two schools in L City in China participated in this study.

\section{Schools}

Two schools were selected through personal contacts: School A and School B. These two schools were selected because of the access to teachers of English who were interested in the research and willing to carry out the experiment designed by the researcher.

\section{Teachers}

One teacher from each of the study schools participated in the experiment: 
Teacher A from School A and Teacher B from School B. They have similar backgrounds and teaching experience: both have taught English in senior middle schools for more than 10 years; both are giving lessons to two classes and working as a class tutor for one of their two classes (a class tutor is responsible for both study and pastoral care of the students).

\section{Students}

Altogether 118 Grade one students participated in this experiment: one class with 55 students ( 24 boys and 31 girls) from School A and one class with 63 students ( 24 boys and 39 girls) from School B. They were the classes of which the participating teachers were class tutors, which they felt would enable easy access to the students.

\subsection{Experimental Material}

New Senior English For China (NSEFC), issued by the People's Education Press, is widely employed as a course book in most senior middle schools around China. Apart from a word list, it contains a part of vocabulary instruction with the vocabulary development exercises, e.g. word-meaning exercises, wordstructure exercises and collation. It aims to serve both teachers and students a systematic guidance in teaching and learning vocabulary. The vocabulary instruction in NSEFC was applied as the experimental material. In other words, the experimental group was supposed to conduct the part of vocabulary instruction instead of skipping it in the class. It is worth noting that most teachers in practice skip the part of vocabulary instruction, including Teacher A and Teacher B, since they assume it unnecessary.

\subsection{Data Collection}

Methodological triangulation was applied to collect data. Specifically, more than one method of data collection was employed in the research: Teacher Log, Student Questionnaire and Follow-up Teacher Interview.

\section{Teacher Log}

In Teacher Log, Teacher A and B were asked to provide information on objects of this lesson and its place within the current sequence of lessons; general impression of the lesson, e.g. strengths and weaknesses of the lessons; idea that vocabulary instruction is conducted in the class and other things that the teacher thinks are worth recording. They were supposed to fill in Teacher Log in every lesson during the experimental period. Records in the Teacher Logs could help the writer investigate both the strengths and weaknesses of vocabulary instruction functioning in vocabulary teaching and learning and its feasibility in the teaching context

\section{Student Questionnaire}

A post-experiment Questionnaire was designed to get the students' general views on vocabulary teaching and learning and their attitude to vocabulary instruction in NSEFC. The Student Questionnaire focused on the following as- 
pects:

- How vocabulary was taught before this experiment and what did they think about it;

- How did they generally learn vocabulary; what were the ways that they felt were helpful for learning vocabulary; what was their difficulty in learning

- vocabulary; and

- How did they think of the experiment.

To make the Questionnaire easy to understand and to allow students the room to express their views freely, taking into consideration of their English proficiency, the Questionnaire was Chinese and they fill it in Chinese if they wished.

\section{Follow-up Teacher Interview}

In order to triangulate the information obtained from the Teacher Log and the Student Questionnaire, an interview with Teacher A and Teacher B was conducted individually.

A structured interview was used as a means of data collection with questions as follows:

- vocabulary teaching methods used prior to this experiment;

- views on vocabulary instruction in NSEFC in terms of its function in teaching vocabulary;

- general comments on the experiment

To ensure that the teachers were well prepared for this interview so that more information could be elicited, the writer e-mailed the list of questions to both teachers prior to the interview.

\section{Results}

The findings from the data collection will be presented. It is worth noting that the term "findings" instead of "results" is employed here because the methods for data collection in this study are mainly qualitative.

\subsection{Findings from the Teacher Log}

To record the students' responses towards the vocabulary instruction in the class, Teacher A and Teacher B were asked to fill in a Teacher Log after each unit. Altogether twelve Teacher Logs (six from Teacher A and six from Teacher B) were collected, which recorded how six units of vocabulary instruction went in their experimental classes. The writer read the Teacher Logs carefully and attention was given to teachers' observation of the students' responses to the vocabulary instruction and their comments on strengths of the vocabulary instruction and difficulties encountered when using them in the class.

To sum up the findings of the Teacher Log, both Teacher A and Teacher B appreciated the vocabulary instruction in NEFC: the class became active and interactive in vocabulary learning; a variety of techniques for vocabulary learning aided the students to learn vocabulary effectively and independently. As Teacher 
A recorded in her Logs, "the students looked very active and did not sit quietly waiting for being spooned as before. I noticed that they learnt to think more about a word when they were exposed to the vocabulary sections"; "Most students felt it easier to understand a new word and could grasp it well in this way". Teacher B used a lot of positive words, such as "reasonable", "helpful" and "effective" to record her general impressions on the lessons with vocabulary instruction. In addition, she wrote in one of her Logs that "it introduced the students some knowledge of word building".

In most circumstances, it was proved that vocabulary instruction was feasible in the targeted teaching and learning context and the main difficulties arising in the class could be summarized as follows:

- Sometimes it was difficult for most students to understand the English instructions in the experimental materials

- Time was limited (It was mentioned twice and both of them happened when vocabulary instruction went with Reading.)

\subsection{Findings from the Student Questionnaire}

By the end of the experiment, a Student Questionnaire in Chinese was distributed to the students with an attempt to find out how the students were normally taught and learn vocabulary and what they thought of this experiment. They were asked to fill in the questionnaire faithfully.

Both Teacher A and Teacher B organized the experimental class to fill the Questionnaire at the end of the class and the return rate was 100 per cent, that is, altogether 55 questionnaires were collected from School A and 63 Questionnaires from School B.

The students from School A and School B stated that they were mainly taught by word lists before the experiment. Not being able to remember the words learned by word lists was identified as their main difficulty in vocabulary learning by nearly the whole class. However, almost half of the students said that they had been used to it and some thought that it was practical for the examination.

When the students were asked whether it would make any difference in their vocabulary learning while learning "vocabulary instruction" (as the experiment did), 92 students, i.e. $78 \%$ students agreed that it did make difference. Table 1 below categorised students' comments on the differences that they thought a vocabulary might bring.

Accordingly, the students were positive towards the idea of vocabulary instruction

Table 1. Students' opinions on the differences that vocabulary instruction brings.

\begin{tabular}{|c|c|c|c|}
\hline Differences that Vocabulary Section brings & School A & School B & Total \\
\hline It introduces effective ways to remember a word & 18 & 22 & 40 \\
\hline It helps to know more about a word & 9 & 13 & 22 \\
\hline It makes the class interesting and active & 4 & 12 & 16 \\
\hline It emphasizes the importance of vocabulary & 4 & 10 & 14 \\
\hline
\end{tabular}


for two main reasons: it made the class interesting and active; and it provided guidance on vocabulary learning.

\subsection{Findings from the Follow-Up Teacher Interview}

An informal interview was arranged with Teacher A and Teacher B separately when their students completed their questionnaires. For the convenience of communication, the interview was conducted in Chinese. The analysis of the interview data was based on the notes taken during the interview.

In the interviews, Teacher A said that she mainly taught vocabulary by word lists prior to the experiment: "Generally I spend about five minutes to teach my students to read the words in a word list first and require them to memorize them after learning the text. Then I have a dictation with them to consolidate their vocabulary". Similarly, Teacher B said that she mainly taught vocabulary by a word list. Differently, Teacher B said: "Apart from teaching my students to read the words in a word list, I sometimes link words in lexical sets, collocations and lexical phrases if class time allows".

When asked their opinions of the experiment, both teachers said that vocabulary instruction stimulated the students' motivation in vocabulary learning and provided both the students and the teachers with systematic guidance to the learning and teaching of vocabulary. However, time constraint was the common difficulty that they encountered in the experiment, which was one of the main reasons why they skip it in NSEFC. They believed that it was better to save the time for grammar or other language skills, e.g. listening, writing. Another main reason was that they felt reluctant to accept the change while they had been used to a word list. Teacher A said: "To be honest, even I feel reluctant to the change though I admit that it is more effective to teach vocabulary by a vocabulary section than by a word list. As a key school, we are facing a severe competition in the National College Entrance Examination and memorizing a word list proves to work for examinations. Besides, I have got used to teaching vocabulary by a word list'. For the same question, Teacher B replied that some students in her class were very low in English proficiency, so it was easier for them to accept a simple word list rather than a relatively complicated vocabulary instruction.

\section{Discussion}

Existing research on effective teaching and learning of vocabulary led to the hypothesis in this study that vocabulary instruction in the course book could provide guidance to the teaching and learning of vocabulary in senior middle schools in China and it should not be skipped. Findings above will be discussed here by exploring the research questions: what is the impact of vocabulary instruction on the teaching and learning of vocabulary in senior middle schools in China; is it feasible in the Chinese teaching and learning context to conduct vocabulary instruction? 


\subsection{Impact on Teaching and Learning of Vocabulary}

The impact will be discussed from the perspectives of the English classroom atmosphere; ways of teaching and learning of vocabulary; and class time.

\subsubsection{Impact on the Atmosphere of English Classroom}

Prior to the experiment, Teacher A and Teacher B mainly taught vocabulary by a word list though Teacher B sometimes used alternative VLS, such as linking words in lexical sets, collocation and lexical phrases. Teaching vocabulary by a word list is a part of teacher-centred model, that is, the teacher is an authority and the students listened to him or her and take notes. In this model, most students act passively in the class and tend to lose their motivation in learning vocabulary. Findings in the student questionnaires suggested that large percentages of the students felt bored by merely being taught by a word list. It confirmed again the findings by many researchers that it is ineffective and unsystematic to teach vocabulary by merely presenting word lists for memorization.

In the experiments, vocabulary instruction was used instead of a word list when teaching vocabulary in the class. With regard to the students' responses to the classes with vocabulary instruction, both Teacher A and Teacher B recorded in their Logs that "the class became active and interactive in vocabulary learning". Most students did not just sit quietly waiting for being spooned as before but act actively to answer and ask questions in the class. Also, many students said in their questionnaires that vocabulary instruction made their class interesting and active and it stimulated their motivation to learn vocabulary. Therefore, it indicates that vocabulary instruction did make a difference. It did make the English class interesting and active and it did stimulate the students' interests in vocabulary learning. Firstly, it was an alternative way to teach vocabulary by vocabulary instruction, so students felt interested in it. It is known that students at the age of sixteen to eighteen are interested in something new to them. They are easily bored by routine teaching and thus their interest in learning may be reduced. However, "the key in all vocabulary teaching is to keep motivation high" (Hatch and Brown, 1995, p. 422) [5]. Secondly, the students perceived that what they learnt in vocabulary instruction was useful to their learning autonomy, so they were motivated. This confirmed the finding by Hatch and Brown (1995) [5] noted that learners are motivated if they have a measure of learning autonomy. For instance, many students said in their questionnaires that in vocabulary instruction they learned more about a word and effective ways to learn vocabulary. Therefore, the transmission of knowledge could shift away from a teacher-centred model by a word list to a student-centred model by an interactive activity based vocabulary instruction. Being the centre in the class, the students could behave actively rather than passively.

\subsubsection{Impact on the Way of Teaching and Learning of Vocabulary}

It is considered that the most obvious impact of vocabulary instruction was to arouse the awareness of various strategies for the teaching and learning of vo- 
cabulary. Prior to the experiment, vocabulary was mainly taught by a word list, so most students knew few VLS apart from a word list. One possible result, as the findings in the Student Questionnaires showed, was that most students were learning vocabulary by a word list though they did not like it. Different from a word list, vocabulary instruction gave students the opportunity to develop a variety of strategies for learning words. Responses from the students showed that the most obvious difference that vocabulary instruction brought was "introducing effective ways to remember a word". From the view of the teachers, Teacher $\mathrm{B}$ in the Follow-up Teacher Interview said, "vocabulary instruction in NSEFC does a great help for the students to grasp a new word and learn the ways of learning words systematically. For me (as a teacher), it is good to my professional development since it provides guidance to teaching vocabulary".

However, it does not mean that a word list is useless and should be dismissed completely. It is effective for examinations and beginners or learners with lower language proficiency. Indeed, the findings from the Student Questionnaires suggested that a word list is practical for examinations. It implies as Richards (1987) [12] mentions, there is not a "right" method which would work for all learners in all contexts. Accordingly, only when the students are exposed to various ways of learning vocabulary can they become aware that there is a wide variety of ways for dealing with vocabulary and choose the appropriate one for them in a certain context. Given the tools for learning vocabulary, the students can become more capable of independent learning and learn how to continue to improve their vocabulary on their own outside of the class. Thus, they can grasp the huge number of lexical items independently in the future.

\subsubsection{Impact on Class Time}

Nation (2001, p. 58) [10] suggests that the average time on vocabulary should not occupy more than $25 \%$ of each lesson. Accordingly, in a 45-minute lesson, it is acceptable if time spending on vocabulary teaching is no more than $13 \mathrm{~min}$ utes. In practice, the vocabulary instruction in the experiments could be finished in 13 minutes. However, findings from the Teacher Logs suggest the problem of time constraint.

Prior to the experiments, vocabulary was mainly taught by a word list, that was, vocabulary was taught by translating its meaning into the nearest mothertongue equivalent. In this way, the students just listened to their teacher and took notes, thus avoiding the difficulty of managing interaction in a large class (more than fifty students). Teacher A said in the Follow-up Teacher Interview that she normally spent only five minutes in teaching vocabulary. However, when vocabulary instruction was employed instead, more knowledge about a word was introduced to the class, which took more time than simply translating its meaning into Chinese. Also, relevant exercises for vocabulary development were followed when knowledge about a word had been introduced. It is conceded that compared with the time on a word list, more class time was needed to finish vocabulary instruction even though it could be finished in 13 minutes. 


\subsection{Feasibility of Vocabulary Instruction}

Accordingly, the feasibility of vocabulary instruction is not constrained by time but heavily by two factors: the present National College Entrance Examination System in China; and institutional resistance to change.

The National College Entrance Examination emphasizes the reproduction of factual information while vocabulary instruction is fundamentally concerned with the development of language skills. All senior middle school students face a severe competition in the examination, which attributes to the fact that China is a country with a large population of 1.4 billion. Only those, as noted, passing the National College Entrance Examination successfully can receive a higher education. Therefore, to ensure students' success in this examination, the teachers have to adopt test-orientated instructions although most of them firmly support the quality education which emphasizes the real ability rather than the reproduction of factual information. In practice, key schools have to stand more pressure of examinations, because it is one of important criteria for evaluating key schools by the local Education Committee. It could be one possible reason that Teacher A mainly taught vocabulary by a word list but seldom used other methods and that certain students in School A considered a word list practical in the examination. This confirmed the conclusion that Cohen (1990) [13] argues that word lists prove to be particularly useful when students study for vocabulary sections of standardized tests. Thus, it is not surprising that it is widely employed by both the teachers and the students although it has proved not effective in terms of real ability.

Apart from the factor of examinations, institutional resistance to the change of vocabulary instruction was perceived from both the students and the teachers. In other words, they admitted the advantages that a vocabulary section could bring, but felt reluctant to accept it. Interestingly, the common reasons for the resistance were different in School A and School B: students in School A said in their Questionnaires that "they have been used to a word list"; students in School B said that "a vocabulary section is difficult". From the view of teachers, Teacher A said in the Follow-up Teacher Interview that she had been used to the teaching of vocabulary by a word list. As for vocabulary instruction, she had to spend more time on the lesson preparation and sometimes she did not feel confident to use a new methodology. Also, vocabulary instruction occupied more class time than a word list did. Then less class time was left for other activities.

Surely, it is not realistic to suggest the teachers and the students ignore the National College Entrance Examination and change their "habit" of word list overnight. However, it is possible to make them perceive the necessity of vocabulary instruction in developing vocabulary for the purpose of communication. The way that a teacher teaches in the class has a great influence on his or her students' learning strategies. Therefore, it is vital to help the teachers change their attitude first. It requires expert training in teaching vocabulary, which includes showing impact of vocabulary instruction, like this study, and demon- 
strating a model lesson with vocabulary instruction.

Therefore, it is worth spending considerable class time on vocabulary instruction. Meanwhile, in a model lesson with vocabulary instruction, the teachers may perceive the obvious difference that a lesson with intervention brings, and they can learn the techniques to deal with vocabulary. At the same time, workshops and seminars should be available for communication between teachers about matters such as vocabulary teaching and learning.

\section{Conclusions}

Gairns and Redman (1986) [14] suggest that vocabulary instruction in EFL course books, where lexical knowledge and VLS are introduced, can provide the teachers and the students with systematic vocabulary guidance. However, most teachers in practice tend to skip it even though it is a section included in the course book. To prove its necessity, the empirical study was conducted to investigate the impact of vocabulary instruction on the teaching and learning of vocabulary in senior middle schools in China. Based on the data collected from the Teacher Log, the Student Questionnaire and the Follow-up Teacher Interview, it has been found: 1) vocabulary instruction could work more effectively than a word list in stimulating the students' interest in vocabulary learning and in developing their vocabulary; 2) National College Entrance Examination System in China and institutional resistance to change are the main reasons that vocabulary instruction is neglected in ELT.

Meanwhile, it must be taken into account that the study has limitations. First, with the element of time constraint, the experimental period was not long enough to make the teachers and the students perceive the apparent difference that vocabulary instruction brought. Second, since this study was involved with only two classes from two schools, this may affect the generalisability of the findings.

In this respect, further studies should include a wider range of research contexts and a longitudinal study may be valuable to investigate the importance of vocabulary instruction. In addition, it is worth pondering whether vocabulary instruction would work as effectively as a word list to help the students pass their examinations. Otherwise it is doubtful if both the teachers and the students will be convinced of the efficacy of the vocabulary instruction in EFL course books.

\section{Acknowledgements}

I gratefully acknowledge Teacher A and Teacher B and their students who kindly agreed to take part in this research. I thank Dr. Mei Lin and Ms. Ann Macdonald for their guidance in editing earlier drafts of this paper. I would also like to express my gratitude to the anonymous reviewers.

\section{Funding}

This research is supported by the Social Science of Ministry of Education, China 
(18YJC880064).

\section{Note on Contributor}

Yuanyuan Zhu is Associate Professor of Foreign Language Education in School of English and Education, Ph.D Candidate at Center for Foreign Literature and Culture, Guangdong University of Foreign Studies, China. Her research interests include vocabulary teaching and comparative study of cultures.

\section{Conflicts of Interest}

The author declares no conflicts of interest regarding the publication of this paper.

\section{References}

[1] Zhu, Y. (2017) Helping Teachers Take Control of a Course Book Facilitating Vocabulary Instruction. Canadian Social Science, 13, 84-93.

[2] Chen, S.F. (2002) Study on Vocabulary Learning Strategies for Chinese English-Majors. Teaching English in China, 25, 17-20.

[3] Dickinson, L. (1992) Learner Training for Language Learning. Authentik Language Learning Resources Ltd., Dublin 2.

[4] Ellis, G. and Sinclair, B. (1989) Learning to Learn English a Course in Learner Training Teacher's Book. Cambridge University Press, Cambridge.

[5] Hatch, E. and Brown, C. (1995) Vocabulary, Semantics, and Language Education. Cambridge University Press, Cambridge.

[6] Anderson, N.J. (1994) Developing Active Readers: A Pedagogical Framework for the Second Language Reading Class. System, 22, 177-194.

https://doi.org/10.1016/0346-251X(94)90055-8

[7] Oxford, R.L. and Scarcella, R.C. (1994) Second Language Vocabulary Learning among Adults: State of the Art in Vocabulary Instruction. System, 22, 231-243. https://doi.org/10.1016/0346-251X(94)90059-0

[8] Schmitt, N. (2000) Vocabulary in Language Teaching. Cambridge University Press, Cambridge.

[9] Goulden, R., Nation, P. and Read, J. (1990) How Large Can a Receptive Vocabulary Be? Applied Linguistics, 11, 341-363. https://doi.org/10.1093/applin/11.4.341

[10] Nation, I.S.P. (2001) Learning Vocabulary in Another Language. Cambridge University Press, Cambridge. https://doi.org/10.1017/CBO9781139524759

[11] Kumar, R. (1996) Research Methodology A Step-By Step Guide for Beginners. Sage Publications, London.

[12] Richards, J. (1987) Beyond Methods: Alternative Approaches to Instructional Design in Language Teaching. Prospect, 3, 11-30.

[13] Cohen, A.D. (1990) Language Learning: Insights for Learners, Teachers, and Researchers. Heinle \& Heinle, Boston, MA.

[14] Gairns, R. and Redman, S. (1986) Working with Words A Guide to Teaching and Learning Vocabulary. Cambridge University Press, Cambridge. 